\title{
The subtle intracapsular survival of the fittest: maternal investment, sibling conflict, or environmental effects?
}

\author{
Kathryn E. Smith ${ }^{1}$ and Sven Thatje \\ University of Southampton, Ocean and Earth Science, National Oceanography Centre, Southampton, European Way, \\ Southampton SO143ZH United Kingdom
}

\begin{abstract}
Developmental resource partitioning and the consequent offspring size variations are of fundamental importance for marine invertebrates, in both an ecological and evolutionary context. Typically, differences are attributed to maternal investment and the environmental factors determining this; additional variables, such as environmental factors affecting development, are rarely discussed. During intracapsular development, for example, sibling conflict has the potential to affect resource partitioning. Here, we investigate encapsulated development in the marine gastropod Buccinum undatum. We examine the effects of maternal investment and temperature on intracapsular resource partitioning in this species. Reproductive output was positively influenced by maternal investment but additionally, temperature and sibling conflict significantly affected offspring size, number, and quality during development. Increased temperature led to reduced offspring number, and a combination of high sibling competition and asynchronous early development resulted in a common occurrence of "empty" embryos, which received no nutrition at all. The proportion of empty embryos increased with both temperature and capsule size. Additionally, a novel example of a risk in sibling conflict was observed; embryos cannibalized by others during early development ingested nurse eggs from inside the consumer, killing it in a "Trojan horse" scenario. Our results highlight the complexity surrounding offspring fitness. Encapsulation should be considered as significant in determining maternal output. Considering predicted increases in ocean temperatures, this may impact offspring quality and consequently species distribution and abundance.
\end{abstract}

Key words: Buccinum undatum; cannibalism; embryology; life history theory; marine gastropods; maternal investment; nurse egg consumption; resource partitioning; sibling rivalry; temperature.

\section{INTRODUCTION}

Offspring fitness is of fundamental importance in selection and consequently, a species' success depends on its ability to reproduce effectively. Selection favors those that produce the largest possible number of surviving young. Traditionally, quality is believed to increase with size, with larger offspring regularly (although not always) showing higher growth rates and survival in marine invertebrates (Rivest 1983, Moran and Emlet 2001, Marshall et al. 2006) and other taxa including birds (Rhymer 1988), insects, reptiles, and plants (Kingsolver and Huey 2008). The increased maternal investment associated with producing larger, fitter young (Vance 1973) does however result in energetic trade-offs occurring (Vance 1973, Smith and Fretwell 1974). Most contemporary life history theory suggests "optimal" offspring size may vary with environmental conditions, and to maximize fitness, mothers will adjust the size and number of offspring

Manuscript received 2 October 2012; revised 14 March 2013; accepted 12 April 2013. Corresponding Editor: J. J. Stachowicz.

1 Present address: Florida Institute of Technology, 150 West University Boulevard, Melbourne, Florida 32901 USA. E-mail: kathryn@fit.edu accordingly (McGinley et al. 1987, Bernardo 1996, Mousseau and Fox 1998). Among other variables, stress, habitat quality, temperature, maternal size, and maternal nutritional status have all been identified as factors affecting the trade-off between size and number of offspring (Hadfield 1989, Marshall and Keough 2007, Crean and Marshall 2009, Kamel et al. 2010b).

Traditionally, maternal output is perceived to be greatest if maternal investment (i.e., the resources invested into offspring by the mother) is even among all offspring; consequently, the assumption is regularly made that the offspring produced by one female are of an equal size and fitness (Thorson 1950, Smith and Fretwell 1974, Bernardo 1996, Parker et al. 2002). In reality, however, intra-clutch variations in offspring size are often observed, and over the past decade have become a popular topic for debate. Within-brood variations in offspring size have now been recognized in diverse species, occurring both between cohabiting embryos exhibiting one developmental mode (e.g., Fox and Czesak 2000, Kudo 2001, Dziminski and Alford 2005, Marshall et al. 2008a), and between cohabiting embryos exhibiting different developmental modes (Poecilogony) (e.g., Gibson et al. 1999, Oyarzun and 
Strathmann 2011, Kesäniemi et al. 2012, Gibson and Carver 2013).

Bet-hedging, in which females inhabiting variable environments produce offspring of a range of sizes or developmental modes, is one of several explanations that have been suggested to explain within-brood variations in offspring size (Slatkin 1974, Philippi and Seger 1989, Koops et al. 2003, Marshall et al. 2008b, Crean and Marshall 2009). The reported differences are typically understood to be a maternal effect, occurring as a direct result of variations in the provisioning allocated to each embryo (Krug et al. 2012). Explanations for this often focus on the environmental factors affecting maternal provisioning (Bernardo 1996, Moran and Emlet 2001), and only rarely have other variables been considered (e.g., Lardies and Fernández 2002, Parker et al. 2002, Fernández et al. 2006, Kamel et al. 2010a, b, Oyarzun and Strathmann 2011). Assuming no poecilogony, species exhibiting intracapsular development often receive maternal provisioning during development in the form of nurse eggs, which are consumed for nutrition. Nutrients may alternatively be allocated at production to each embryo, or be obtained from intracapsular fluids or capsule walls (Ojeda and Chaparro 2004). Within each capsule, embryos are usually equal in their ability to consume, and therefore, intracapsular size variations are rarely observed (Spight 1976, Rivest 1983, Chaparro and Paschke 1990, Strathmann 1995). Within-brood variation in offspring size is instead achieved through irregular allocation of nurse eggs and embryos to capsules (Thorson 1950, Spight 1976, Rivest 1983). However, in a handful of species, size differences have been observed between the adelphophagic or direct developing embryos in one capsule (Portmann 1925, Gallardo 1979, González and Gallardo 1999, Strathmann and Strathmann 2006, Cumplido et al. 2011, Smith and Thatje 2013). Within a capsule, individuals, which consume more nutritional reserves, inevitably hatch at a larger size, and are typically understood to have a greater chance of survival. In these examples, the differences typically occur as a result of competition for intracapsular resources, or occasionally through cannibalism of partly developed siblings. Some maternal control may exist; for example, some spionid polychaetes manually open egg capsules to limit cannibalism (e.g., Kamel et al. 2010b, Oyarzun and Strathmann 2011), but maternal effect may not always be the primary determinate of individual offspring fitness. An alternative source of variation is sibling conflict, although in the oceans this is rarely considered a significant factor, and as a result has received little attention to date (e.g., Parker et al. 2002, Kamel et al. $2010 a, b)$.

Of particular interest is the intracapsular resource partitioning in Buccinum undatum, a common and commercially important North Atlantic gastropod. This species exhibits direct development, which is initially asynchronous, with no observed poecilogony. Nurse eggs are the primary nutritional reserve available throughout this period (Valentinsson 2002, Smith and Thatje 2013). To our knowledge, in other species exhibiting intracapsular development, all embryos obtain nutrition of some form, either incorporated into the egg during production, during intracapsular development, or during a later planktotrophic developmental stage (Gallardo 1979, González and Gallardo 1999, Kamel et al. 2010b, Cumplido et al. 2011). In contrast to most species however, large intracapsular size differences have been observed between offspring, resulting in large size differences at hatching (Fig. 1a; Portmann 1925, Smith and Thatje 2013). Additionally, common occurrences of "empty" embryos have been reported (but not quantified) inside capsules (Fig. 1b), whereby some embryos do not consume any nurse eggs during development (Smith and Thatje 2013). These embryos often successfully complete early development, but do not survive to hatching, indicating an unusual example of sibling conflict. Lack of survival has been observed through the presence of small, thin empty shells, and the absence of live empty embryos after the pediveliger stage (Smith and Thatje 2013; K. E. Smith and S. Thatje, unpublished data). Sibling conflict may be reflected in the variety in number of nurse eggs consumed by different offspring and the occurrence of empty embryos (embryos that did not succeed in acquiring any nutrition at all). Furthermore, evidence suggests the proportion of empty embryos to be accentuated by increased temperature (Smith et al. 2013), suggesting environmental factors may play a significant role in intracapsular resource partitioning, contributing to the variations resulting from sibling conflict. Considering this, predicted increases in seawater temperature (Hughes et al. 2010) could lead to a reduction in the number of individuals that successfully develop, potentially affecting species abundance. This rare example demonstrates a different effect of encapsulation, the unusual nature of which remains undescribed.

Understanding the dynamics contributing to developmental resource partitioning in offspring is of great significance, in both the evolutionary and ecological context. Here, we contribute to the discussion of the evolution of egg size and offspring size in marine invertebrates, with emphasis on the rarely considered effects of sibling conflict. We investigate the unusual intracapsular resource partitioning reported in $B$. undatum. We use this species to compare the consequences of maternal investment and environmental effects on sibling conflict during intracapsular development.

\section{Materials And Methods}

\section{Study species}

Buccinum undatum is a common North Atlantic shallow-water gastropod. Over the past few decades it has become an increasingly important commercial species in North America and the UK, with global 

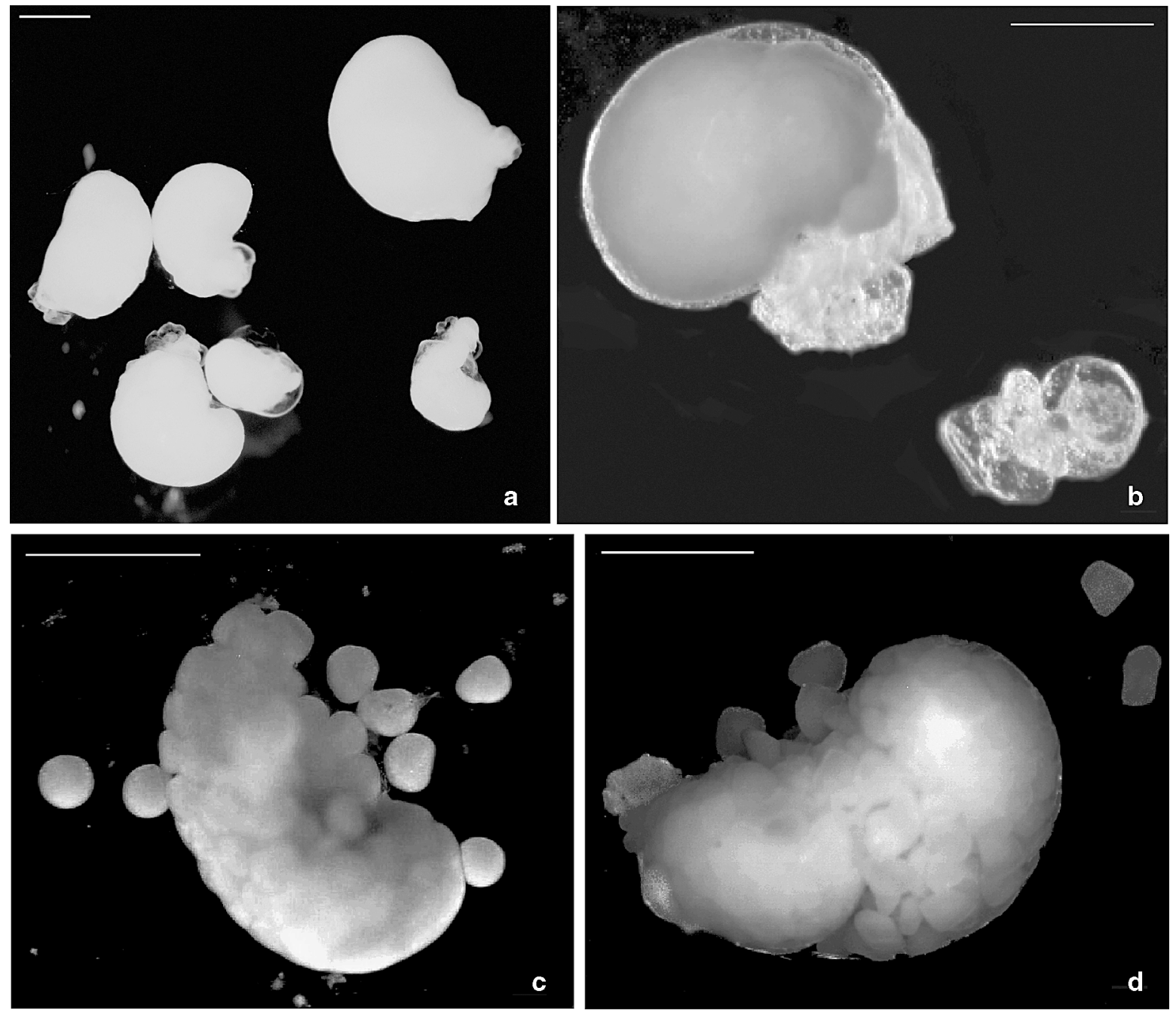

FIG. 1. Images of the marine gastropod Buccinum undatum during development. (a) Embryos of varying sizes developing alongside each other, within one capsule and following nurse egg consumption. (b) A normal veliger next to an "empty" veliger from the same capsule. The empty veliger is visibly lacking nurse eggs inside its midgut. (c) A pierced embryo displaying intact nurse eggs spilling out. (d) A "victim" of cannibalism bursting out of the midgut of its consumer. Scale bars represent $500 \mu \mathrm{m}$.

demand continuously rising (Lawler and Vause 2009; Department of Marine Resources, available online). ${ }^{2}$ The southern end of its distribution falls around the south coast of the UK, where many local fisheries depend on income from this species (Lawler and Vause 2009). Here, the common whelk is a winter spawner, with egg laying and complete development occurring when water temperatures are at their lowest, ranging $\sim 4-10^{\circ} \mathrm{C}$ (Smith and Thatje 2013). Females group to lay; each one produces between 80 and 150 egg capsules, which collectively create large egg masses containing up to thousands of capsules. Maternal provisioning to each capsule increases with female size; larger females produce larger capsules, which contain a greater number of nurse eggs and embryos. Each capsule contains

\footnotetext{
${ }^{2}$ www.maine.gov/dmr/rm/whelks.html
}

between approximately 500 and 2600 eggs, of which between approximately 2 and 21 develop into embryos. Initial development is asynchronous and within a capsule there may be several days between the first and last embryos beginning nurse egg consumption. Following this, total nurse egg consumption within a capsule occurs over $\sim 2-5$ days, depending on temperature. Development becomes synchronous during the veliger stage, following nurse egg consumption. Across the entire species range, total intracapsular development takes between 2.5 and 8 months (Martel et al. 1986, Smith and Thatje 2013, Smith et al. 2013).

\section{Egg mass farming and maintenance}

Buccinum undatum egg masses were farmed in the seawater aquarium at the National Oceanography Centre, Southampton, as described by Smith and Thatje 
(2013). Adult whelks were collected by Viviers from the Solent, UK $\left(50^{\circ} 39^{\prime} \mathrm{N}, 001^{\circ} 37^{\prime} \mathrm{W}\right)$ in late November 2010 using whelk traps $(\sim 15 \mathrm{~m}$ depth) (available online). ${ }^{3}$ Egg laying occurred predominantly at water temperatures below $8^{\circ} \mathrm{C}$, with each egg mass being contributed to by several females. Egg masses were removed from aquarium walls 24 hours after laying had ceased.

Because the number of nurse eggs and embryos per capsule is positively correlated with capsule size in $B$. undatum, (Valentinsson 2002, Smith and Thatje 2013), egg masses were divided into size classes depending on capsule volume (calculated according to Smith and Thatje 2013). Capsules with volumes of $<100 \mathrm{~mm}^{3}$ were classified as small, between 100 and $200 \mathrm{~mm}^{3}$ were classified as medium, and above $200 \mathrm{~mm}^{3}$, as large. Egg masses were maintained in separate $1.8-\mathrm{L}$ incubation tanks containing aerated, $1-\mu \mathrm{m}$ filtered seawater. Each tank was acclimated stepwise to one of four temperatures $\left(6,10,14,18^{\circ} \mathrm{C} ; 1^{\circ} \mathrm{C}\right.$ temperature change every 24 hours), with capsules from every size class being developed at $10^{\circ} \mathrm{C}$ and only medium capsules being developed at all other temperatures.

\section{Intracapsular resource partitioning}

Development was assessed according to Smith and Thatje (2013). Egg masses were inspected twice a week until early veligers became visible through the semitransparent capsule walls. They were then examined daily until all nurse eggs had been consumed. At temperatures ranging from $6^{\circ}$ to $18^{\circ} \mathrm{C}$, total nurse egg consumption in B. undatum has been shown to take between approximately 2 and 5 days (Smith et al. 2013). If nurse egg consumption appeared not to have ended 24 hours after the expected completion time for the experimental temperature, then when dissected, only capsules containing veligers (which were too developed to continue nurse egg consumption) were examined (see Smith and Thatje [2013] for developmental stages). Fifteen capsules were randomly dissected from every mass; the number of embryos inside each was counted; and the proportion of empty embryos determined (classified as individuals who had consumed $\leq 1$ nurse egg). Any nurse eggs, which had been consumed, were visible inside an embryo as yellow balls inside the translucent embryo body. Empty embryos could therefore be determined without dissection (Fig. 1b).

Nurse egg partitioning.- In order to assess nurse egg partitioning, the embryos from 10 of these capsules were individually dissected. Following initial consumption, in $B$. undatum nurse eggs are stored undamaged in the midgut prior to use, allowing number of eggs consumed to be easily distinguished. The outer membrane of the embryo was pierced, letting the consumed nurse eggs spill out (Fig. 1c), and allowing the number of nurse

\footnotetext{
${ }^{3}$ www.fishmarketportsmouth.co.uk
}

eggs to be counted. For each capsule, the range in number of eggs consumed within a capsule was also established, by subtracting the lowest number of eggs consumed by an embryo from the highest number of eggs consumed by an embryo.

Embryo dry mass.-The embryos from the remaining five capsules were removed, stored individually in preweighed $(6 \times 4 \mathrm{~mm})$ tin capsules, and frozen at $-80^{\circ} \mathrm{C}$. Only embryos containing more than one nurse egg were sampled, since empty embryos were very fragile and were regularly damaged during sampling. A minimum of 30 embryos was weighed from each mass. If this number was not achieved from the five capsules already open, additional capsules were opened to obtain sample numbers. Samples were later freeze-dried over 24 hours and then dry mass (DM) was determined on a microbalance (accurate to $1 \mu \mathrm{g}$ ) to assess changes in mean embryo mass with temperature.

Elemental composition.-Elemental analysis was carried out on embryos in order to assess bioenergetics. Elemental carbon (C) and nitrogen (N) correlate to lipid and protein levels, and therefore indicate the physiological condition of an organism. Changes in structure and metabolic machinery are reflected by $\mathrm{N}$, and information on nutritional reserves provided by C (Anger 2001). Twenty-five of the freeze-dried samples from each condition were analyzed using a Fison (Carlo Erba, Milan, Italy) 1108 elemental analyzer. The analyzer was calibrated using chitin as a standard $(\% \mathrm{C}, 44.71 ; \% \mathrm{~N}$, 6.79). Proportions of $\mathrm{C}$ and $\mathrm{N}$ were determined during analysis, and biomass of each was then calculated.

\section{Maximum consumption}

The maximum number of nurse eggs a veliger was capable of consuming was assessed from the content of 15 medium capsules randomly selected from an egg mass developed at $10^{\circ} \mathrm{C}$. As soon as early veligers became visible inside a capsule, the translucent marginally concave face of the capsule was removed, leaving the deeper, ribbed face. All but one of the early veligers was removed from the capsule. This embryo remained with the unconsumed nurse eggs in a covered petri dish filled with pre-incubated $\left(10^{\circ} \mathrm{C} ; 1 \mu \mathrm{m}, 12 \mathrm{~h} \mathrm{UV}\right.$-filtered) seawater until it had reached the veliger stage and nurse egg consumption was no longer possible. At this point the embryo was dissected as described previously, and the number of consumed eggs determined.

\section{Statistics}

Empty embryos were included in counts for all data except dry masses and elemental $(\mathrm{C}, \mathrm{N})$, due to the small size, and therefore mass of these individuals.

A nonparametric Kruskal-Wallis one-way analysis of variance was used to compare number of embryos developing per capsule, number of nurse eggs consumed per embryo, embryo DM, and proportion of empty embryos to developmental temperature and capsule size. The number of nurse eggs consumed by embryos 
developing in small, medium, and large capsules at $10^{\circ} \mathrm{C}$ was also compared to the number of nurse eggs consumed by the maximum consumption embryos. A nonparametric test was used due to unbalanced and unmatched data sets for number of nurse eggs consumed per embryo and embryo DM. Post hoc analysis was carried out using Dunn's test. Because both C and N masses were determined using DM, an analysis of covariance was carried out (using DM as a covariate), to examine relationships between $\mathrm{C}$ and $\mathrm{N}$, and developmental temperature or capsule size. Data transformation $(1 / x)$ was carried out prior to analysis of covariance. Regression analysis was used on all $10^{\circ} \mathrm{C}$ samples (all capsule sizes) to examine relationships between proportion of empty embryos, and number of embryos per capsule and capsule volume. Range in number of eggs consumed by embryos was also compared to number of embryos per capsule, capsule volume, and total number of nurse eggs per capsule (determined by summing the number of nurse eggs consumed by all embryos in a capsule). Multiple and independent regression analysis was carried out to compare the dependent variables (proportion of empty embryos and range in number of eggs consumed) to the above factors.

\section{Buccinum undatum from Breiðafjörður, Iceland}

Four egg masses (medium capsule size) were hand collected from beaches around Breiðafjörður, Iceland, near the northern end of the species distribution. These samples had developed naturally at temperatures ranging $3-4^{\circ} \mathrm{C}$, and were used for an interpopulation comparison. Number of early veligers per capsule (26 capsules) and early veliger dry masses (seven capsules, eight samples per capsule) were sampled from capsules with a volume of $100-200 \mathrm{~mm}^{3}$. These data were used only as a comparison and no statistical analysis was carried out.

\section{Results}

\section{Embryo midgut content}

During development, B. undatum embryos engulf nurse eggs and store them in the midgut, conserved whole for later nutritional use. When embryos were pierced to enable nurse eggs to be counted, on three separate occasions an early veliger was found inside, indicating it to have been consumed by the more developed embryo.

\section{Intracapsular resource partitioning}

In total, 170, 116, 124, and 78 embryos were dissected from medium capsules at $6^{\circ}, 10^{\circ}, 14^{\circ}$, and $18^{\circ} \mathrm{C}$, respectively (10 capsules per temperature), and 47 and 257 embryos were dissected from small and large capsules, respectively $\left(10^{\circ} \mathrm{C} ; 10\right.$ capsules per size class $)$. All embryos from every capsule examined were alive. Masses were collected from 52, 56, 38, and 30 embryos from medium capsules at $6^{\circ}, 10^{\circ}, 14^{\circ}$, and $18^{\circ} \mathrm{C}$, respectively (five capsules per temperature), and 31 and 78 embryos from small and large capsules, respectively $\left(10^{\circ} \mathrm{C}\right.$; nine small capsules, five large capsules) and 56 embryos from the Iceland population. Patterns showed mean number of embryos to decrease with increasing temperature (across both populations) and increased with capsule size (Fig. 2a, b). In contrast, proportion of empty embryos increased with both increasing temperature and capsule size. Mean number of nurse eggs per embryo, embryo DM, and $\mathrm{C}$ and $\mathrm{N}$ increased between $6^{\circ}$ and $14^{\circ} \mathrm{C}$, before decreasing at $18^{\circ} \mathrm{C}$. When comparing capsule size, each of these variables was greatest in medium capsules (Table 1, Fig. 2c, d). Mean embryo dry mass for the Iceland population was between that observed at $6^{\circ}$ and $10^{\circ} \mathrm{C}$ for the Solent population. In every capsule examined, of each size and at each developmental temperature, a large range was observed in number of eggs consumed by any one embryo (Table 2, Figs. 3 and $4 a, b$ ). Across all capsules, (excluding the maximum consumption experiment), individual embryos consumed between 0 and 260 nurse eggs. Empty embryos were commonly observed at every temperature and in all capsule sizes. At $18^{\circ} \mathrm{C}$, every capsule opened contained additional nurse eggs, which had not been consumed by developing embryos. These embryos had developed to the point at which no further nurse egg consumption was possible, before all nurse eggs had been consumed. Embryos developing at $18^{\circ} \mathrm{C}$ consumed fewer nurse eggs than embryos developing at any other temperature.

Analysis indicated number of embryos per capsule ( $H$ $=23.48, P \leq 0.001)$, number of nurse eggs per embryo $(H=144.78, P \leq 0.001), \mathrm{DM}(H=37.61, P \leq 0.001)$, and proportion of empty embryos $(H=25.59, P \leq$ $0.001)$ to be significantly affected by temperature. Post hoc analysis (Fig. 2a, b) showed all $18^{\circ} \mathrm{C}$ data to be significantly different to all other temperatures $(P \leq$ $0.05)$. For all variables except number of nurse eggs per embryo, $6^{\circ} \mathrm{C}$ data also differed significantly from $14^{\circ} \mathrm{C}$ data $(P \leq 0.05)$. Analysis indicated number of embryos per capsule $(H=38.91, P \leq 0.001)$, number of nurse eggs per embryo $(H=35.54, P \leq 0.001)$, DM $(H=$ $10.87, P \leq 0.005)$, and proportion of empty embryos ( $H$ $=15.40, P \leq 0.001)$ to be significantly affected by capsule size. Post hoc analysis (Fig. 2a, b) showed all data to differ significantly between all capsule sizes $(P \leq$ $0.05)$.

Multiple regression analysis, which considered all independent variables in one test, indicated at least one independent variable (number of embryos per capsule, capsule volume, or total number of nurse eggs per capsule) to significantly affect range in number of eggs consumed by embryos within a capsule $(P \leq 0.01)$. Multiple regression analysis also indicated at least one independent variable (number of embryos per capsule or capsule volume) to significantly affect proportion of empty embryos $(P \leq 0.001)$. Independent regression analysis, comparing dependent variables to each inde- 

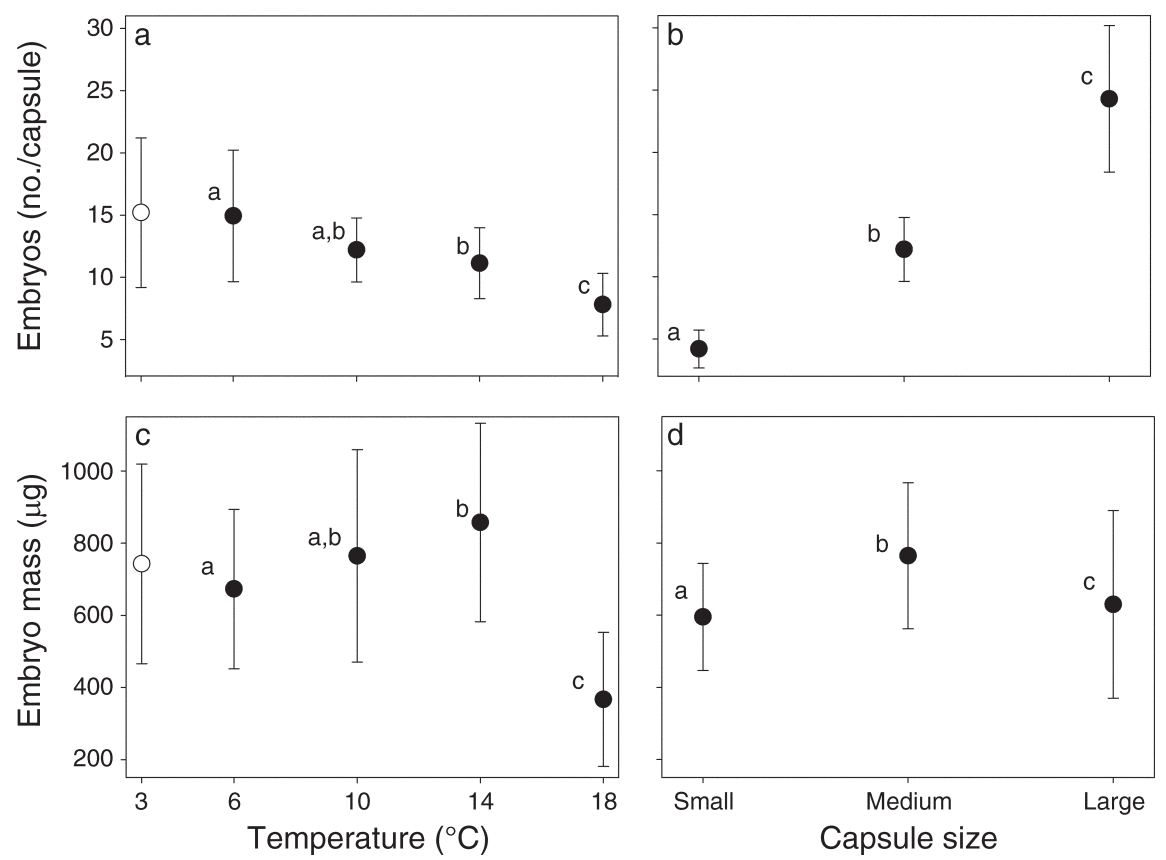

FIG. 2. Number of Buccinum undatum embryos per capsule developing (a) under different temperatures and (b) in differentsized capsules, and embryo mass measurements from (c) different temperatures and (d) different-sized capsules. Solid circles represent data collected from egg masses from the Solent, UK. Open circles represent data collected from Breiðafjörður, Iceland. For each plot $(\mathrm{a}-\mathrm{d})$, different lowercase letters indicate values that are significantly different $(P<0.05)$ as indicated using a nonparametric Kruskal-Wallis one-way ANOVA with post hoc analysis (Dunn's test). Analysis was carried out on Solent samples only. Values are means \pm SD. "Empty" embryos are included in embryo per capsule counts but not embryo mass measurement.

pendent variable separately, confirmed a significant relationship between each independent variable and either range in number of eggs consumed by embryos within a capsule or proportion of empty embryos $(P \leq$ 0.001).

Analysis of covariance indicated both $\mathrm{C}$ and $\mathrm{N}$ masses to be significantly affected to embryo DM under all conditions $(P \leq 0.001)$. Both values were also signifi- cantly affected by developmental temperature $(P \leq$ 0.001). A significant effect for capsule size was not demonstrated for $\mathrm{C}(P=0.064)$ and no effect of capsule size was observed for $\mathrm{N}(P=0.729)$.

\section{Maximum consumption}

"Maximum consumption" embryos consumed between 245 and 325 nurse eggs (Fig. 4a, b). This was

TABle 1. Number of embryos per capsule, dry mass (DM), contents of carbon (C), and nitrogen (N) by capsule size and developmental temperature for embryos of the marine gastropod Buccinum undatum.

\begin{tabular}{|c|c|c|c|c|c|c|c|c|c|c|c|}
\hline \multirow{2}{*}{$\begin{array}{l}\text { Capsule size and } \\
\text { temperature }\end{array}$} & \multicolumn{2}{|c|}{$\begin{array}{l}\text { No. embryos } \\
\text { per capsule } \dagger\end{array}$} & \multicolumn{3}{|c|}{$\mathrm{DM}(\mu \mathrm{g}) \dagger$} & \multicolumn{2}{|c|}{$\begin{array}{c}\mathrm{C}(\mu \mathrm{g} / \text { individual }) \\
(n=25)\end{array}$} & \multicolumn{2}{|c|}{$\begin{array}{c}\mathrm{N}(\mu \mathrm{g} / \text { individual }) \\
(n=25)\end{array}$} & \multicolumn{2}{|c|}{$\begin{array}{c}\mathrm{C}: \mathrm{N} \text { ratio } \\
(n=25)\end{array}$} \\
\hline & Mean & SD & Mean & SD & $n$ & Mean & SD & Mean & SD & Mean & $\mathrm{SD}$ \\
\hline \multicolumn{12}{|l|}{ Small } \\
\hline $10^{\circ} \mathrm{C}$ & 4.2 & 1.52 & 595.2 & 148.23 & 31 & 317.2 & 57.98 & 65.3 & 12.09 & 4.9 & 0.04 \\
\hline \multicolumn{12}{|l|}{ Medium } \\
\hline $6^{\circ} \mathrm{C}$ & 14.9 & 5.28 & 673.1 & 203.72 & 52 & 354.5 & 86.93 & 69.1 & 17.04 & 5.1 & 0.06 \\
\hline $10^{\circ} \mathrm{C}$ & 12.2 & 2.60 & 764.7 & 294.47 & 56 & 411.0 & 132.07 & 82.6 & 27.20 & 5.0 & 0.07 \\
\hline $14^{\circ} \mathrm{C}$ & 11.1 & 2.85 & 857.2 & 274.87 & 38 & 474.4 & 147.44 & 93.8 & 30.18 & 5.1 & 0.11 \\
\hline $18^{\circ} \mathrm{C}$ & 7.8 & 2.51 & 367.0 & 202.15 & 30 & 231.0 & 88.21 & 46.8 & 18.07 & 4.9 & 0.11 \\
\hline \multicolumn{12}{|l|}{ Large } \\
\hline $10^{\circ} \mathrm{C}$ & 24.3 & 5.89 & 629.7 & 259.84 & 78 & 359.9 & 139.05 & 73.4 & 29.45 & 4.9 & 0.08 \\
\hline $3^{\circ} \mathrm{C}$ (Iceland data) & 15.2 & 6.01 & 742.8 & 276.56 & 56 & $\ldots$ & $\ldots$ & $\ldots$ & $\ldots$ & $\cdots$ & $\ldots$ \\
\hline
\end{tabular}

Notes: For embryo numbers per capsule, sample size is $n=15$ capsules per treatment in this study, and $n=26$ capsules for the Iceland data. Mean embryo masses are taken only from embryos that have consumed $>1$ nurse egg. Ellipses indicate that data were not available.

$\dagger$ Kruskal-Wallis one-way analysis of variance indicates results to be significantly affected by both developmental temperature and by capsule size $(P \leq 0.005)$. 
TABLE 2. Range and number of nurse eggs consumed by Buccinum undatum embryos developed at temperatures ranging from $6^{\circ}$ to $18^{\circ} \mathrm{C}$ and in small, medium, and large capsules.

\begin{tabular}{|c|c|c|c|c|c|c|c|c|}
\hline \multirow{3}{*}{$\begin{array}{c}\text { Capsule } \\
\text { size and } \\
\text { temperature }\end{array}$} & \multirow{3}{*}{$\begin{array}{l}\text { No. embryos } \\
\text { dissected }(n)\end{array}$} & \multicolumn{6}{|c|}{ Number of eggs consumed per embryo } & \multirow{3}{*}{$\begin{array}{c}\text { Capsules } \\
\text { containing } \\
\text { embryos with } \\
\leq 1 \text { nurse egg }(\%) \dagger\end{array}$} \\
\hline & & \multirow{2}{*}{$\begin{array}{c}\text { Range } \\
\text { across } \\
\text { all capsules }\end{array}$} & \multicolumn{2}{|c|}{$\begin{array}{l}\text { Minimum range } \\
\text { in one capsule }\end{array}$} & \multicolumn{2}{|c|}{$\begin{array}{l}\text { Maximum range } \\
\text { in one capsule }\end{array}$} & \multirow{2}{*}{$\begin{array}{l}\text { Mean no. eggs } \\
\text { eaten by one } \\
\text { embryo in } \\
\text { one capsule } \uparrow\end{array}$} & \\
\hline & & & $\begin{array}{l}\text { No. } \\
\text { embryos }\end{array}$ & $\begin{array}{c}\text { Range } \\
\text { (no. eggs eaten) }\end{array}$ & $\begin{array}{l}\text { No. } \\
\text { embryos }\end{array}$ & $\begin{array}{c}\text { Range } \\
\text { (no. eggs eaten) }\end{array}$ & & \\
\hline \multicolumn{9}{|l|}{ Small } \\
\hline $10^{\circ} \mathrm{C}$ & 47 & $0-174$ & 6 & $30(48-78)$ & 4 & $173(1-174)$ & 77.0 & 20 \\
\hline \multicolumn{9}{|l|}{ Medium } \\
\hline $\begin{array}{l}6^{\circ} \mathrm{C} \\
10^{\circ} \mathrm{C} \\
14^{\circ} \mathrm{C} \\
18^{\circ} \mathrm{C}\end{array}$ & $\begin{array}{r}170 \\
116 \\
124 \\
78\end{array}$ & $\begin{array}{l}1-239 \\
0-182 \\
0-260 \\
0-92\end{array}$ & $\begin{array}{r}15 \\
10 \\
10 \\
4\end{array}$ & $\begin{array}{l}38(20-58) \\
67(76-143) \\
60(49-109) \\
22(5-27)\end{array}$ & $\begin{array}{r}14 \\
9 \\
16 \\
12\end{array}$ & $\begin{aligned} 138 & (20-158) \\
182 & (0-182) \\
243 & (17-260) \\
92 & (0-92)\end{aligned}$ & $\begin{array}{r}102.3 \\
112.6 \\
148.9 \\
42.4\end{array}$ & $\begin{array}{l}13 \\
40 \\
67 \\
87\end{array}$ \\
\hline \multicolumn{9}{|l|}{ Large } \\
\hline $10^{\circ} \mathrm{C}$ & 257 & $0-187$ & 35 & $86(0-86)$ & 27 & $186(0-186)$ & 62.22 & 87 \\
\hline
\end{tabular}

Notes: Number of embryos dissected ( $n$ ) refers to all columns except the farthest right column. For the percentage of capsules containing embryos with $\leq 1$ nurse egg, $n=15$ for all conditions.

$\dagger$ Kruskal-Wallis one-way analysis of variance indicates results to be significantly affected by both developmental temperature and by capsule size $(P \leq 0.005)$.

significantly different from the number of eggs consumed by embryos developing naturally at $10^{\circ} \mathrm{C}$, in either small, medium, or large capsules $(P \leq 0.001)$. All maximum consumption embryos consumed more nurse eggs than any individual that developed naturally at any temperature, apart from one individual that developed at $14^{\circ} \mathrm{C}$ who consumed 260 eggs.

\section{DisCUSSION}

Developmental resource partitioning in marine invertebrates is of fundamental importance and the resulting variations in offspring size may be of both ecological and evolutionary significance. One hypothesis for the fluctuation of maternal provisioning given to offspring from one clutch in a variable environment is bet-hedging (Slatkin 1974, Philippi and Seger 1989, Koops et al. 2003, Marshall et al. 2008b, Crean and Marshall 2009).
Other hypotheses include selection for differing capabilities, as is observed with poecilogony, and unequal allocation of resources to offspring (e.g., Rivest 1983, Gibson et al. 1999, Oyarzun and Strathmann 2011). Explanations for these patterns often focus on maternal investment, and the influence that environmental factors have on maternal investment (Bernardo 1996, Moran and Emlet 2001), with less attention being paid to the effect of competition among siblings on size variation (e.g., Parker et al. 2002, Kamel et al. 2010a,b). Our results highlight the adverse effects that sibling rivalry can have on offspring size, number and quality, and additionally, emphasize that not only maternal investment, but also environmental factors to significantly affect resource partitioning during intracapsular development. Buccinum undatum provides an example of the
FIG. 3. Typical nurse egg partitioning between embryos in one Buccinum undatum capsule. Numbers along the $x$-axis represent individual embryos from within one capsule. Each bar indicates the number of nurse eggs consumed by an individual embryo. Embryos developed at $10^{\circ} \mathrm{C}$, in a medium-sized capsule.

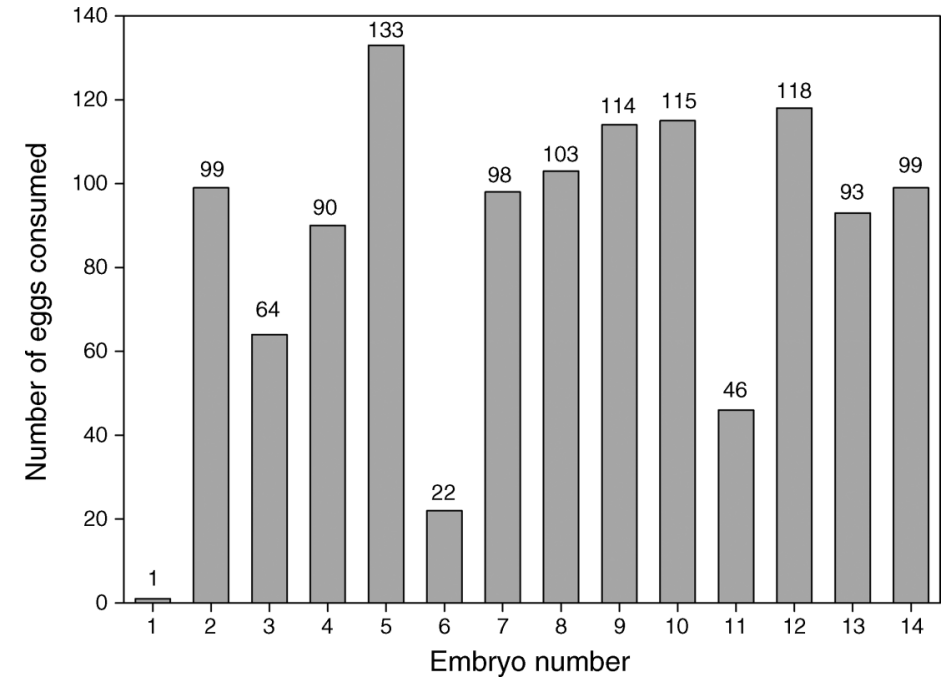



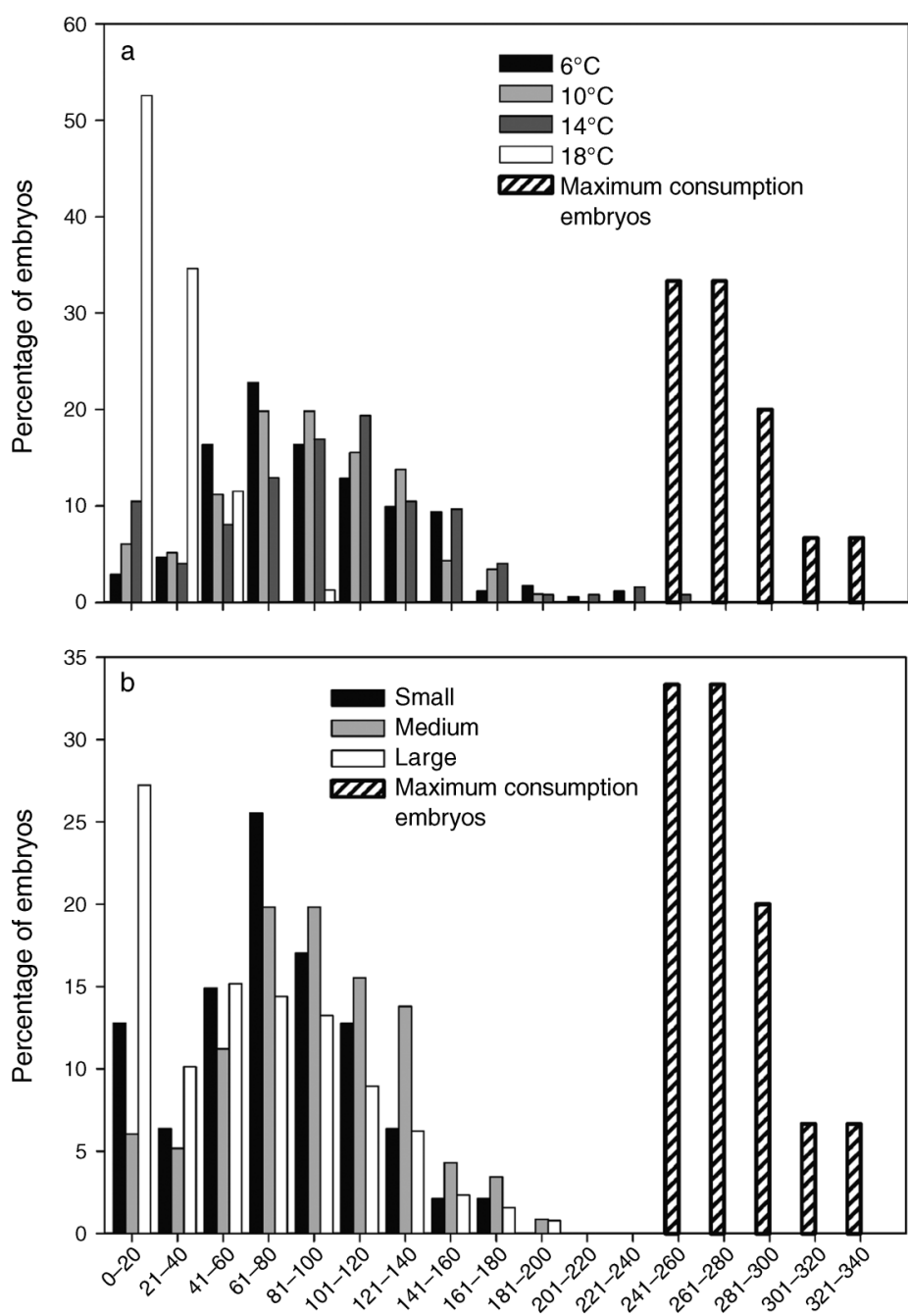

FIG. 4. Percentage of Buccinum undatum embryos consuming different quantities of nurse eggs. (a) Bars with solid shading depict embryos developed at temperatures ranging from $6^{\circ}$ to $18^{\circ} \mathrm{C}$. (b) Bars with solid colors depict embryos developed in small, medium, or large capsules. $(a, b)$ Bars with diagonal lines depict embryos from the maximum consumption experiment. Data include empty embryo counts. Statistical analysis indicated the number of nurse eggs consumed per embryo to be significantly affected by temperature and capsule size, and number of eggs consumed by maximum consumption embryos to be significantly greater than those consumed by embryos developing naturally at $10^{\circ} \mathrm{C}$ from any sized capsule $(P \leq 0.001)$.

Number of eggs consumed by one embryo

varied potential outcomes of encapsulation and also an unusual and novel kind of sibling cannibalism.

The process of encapsulation allows for an elevated occurrence of sibling-to-sibling interaction, which presents a high potential for competition (Marshall and Keough 2007). Examples of species with variable resource partitioning within a capsule are rare, but have been reported in cases of poecilogony (Kamel et al. 2010b, Oyarzun and Strathmann 2011), sibling cannibalism, or arrested development in siblings (Strathmann and Strathmann 2006, Kamel et al. 2010b, Oyarzun and Strathmann 2011), or through varied nurse egg consumption by embryos (Portmann 1925, Gallardo 1979, González and Gallardo 1999, Cumplido et al. 2011, Smith and Thatje 2013). In the Muricidae, in which this latter example is typically observed (e.g., Gallardo 1979, González and Gallardo 1999, Cumplido et al. 2011), intracapsular sizes are variable, but to our knowledge all offspring receive some nutrition. The differences seen have been attributed to competition, which occurs over the weeks or months of nurse egg consumption during development (e.g., Cumplido et al. 2011). In the buccinid $B$. undatum, intracapsular size differences are accentuated by the particularly rapid nurse egg consumption (typically 2-5 days) and the asynchrony in early development, observed in this species. Asynchronous development may result from the process of fertilization and egg distribution during encapsulation. The resulting inequality in developmental stage and nurse egg consumption, can be hypothesized to be favored by selection, or simply to be a by-product of reproduction in B. undatum. The earliest developers have a significant advantage over later developers, and the most delayed embryos regularly develop after all nurse eggs have been consumed (Smith and Thatje 2013). Although asynchronous development is not uncommon (e.g., Fernández et al. 2006), nurse egg consumption is typically slower. Usually, asynchrony within a capsule is compensated for by the slower nurse egg consumption, leading to smaller intracapsular size variations than is observed in $B$. 
undatum. This selection for the fittest inhibits the number of embryos successfully developing, as some outcompete others for the limited resources available.

Maternal provisioning to a capsule typically increases with both female and capsule size (Valentinsson 2002, Smith and Thatje 2013). In the present study, a higher total number of embryos developing per capsule was observed, but this was offset to a large degree by the increased proportion of empty embryos observed in conjunction. The increased occurrence of empty embryos and the lower mean mass observed in larger capsules suggests a lower nurse egg to embryo ratio. Consequently, embryos developing in medium capsules appeared to be better off; these individuals were on average larger and fitter than individuals in either large or small capsules. This may indicate that medium capsule sizes, and therefore intermediate numbers of embryos, are most beneficial for developing offspring. However, future work is necessary to test if this is an adaptive trend. Interestingly, the high number of eggs consumed by each embryo in the maximum consumption experiment indicated embryos to be capable of consuming many more nurse eggs than they naturally succeeded to do inside a capsule of any size. No "large" embryos appear to develop naturally, in B. undatum, only "medium" and "small."

Environmental factors play an important role in shaping life history. They affect not only maternal investment but also impact offspring growth and survival (Koops et al. 2003, Anger et al. 2004, Marshall and Keough 2007, Crean and Marshall 2009). Environmentally induced changes in offspring size or number occurring during embryonic development have, however, rarely been discussed in the context of life history theory (Lardies and Fernández 2002, Kamel et al. 2010b, Oyarzun and Strathmann 2011). Our results indicate a temperature-mediated shift in number of embryos developing, embryo mass and bioenergetic content, and proportion of empty embryos within a capsule. Comparisons can be drawn to the poecilogonic spionid polychaete Boccardia proboscidea. Cannibalism of small planktotrophic offspring by large adelphophagic (nurse egg consuming) offspring increases with duration of encapsulation, and consequently, the number of individuals hatching is reduced, but their average size increases. Time of hatching is dependent on environmental temperature and is decided by the mother, who tears open each capsule (Kamel et al. 2010b, Oyarzun and Strathmann 2011). In this example, and as is typically seen in marine invertebrates, a larger number of smaller offspring were produced under warmer condition. This observation is regularly attributed to maternal investment (Thorson 1950, Clarke 1992, Marshall and Keough 2007, Marshall et al. 2008a) and for $B$. proboscidea, is also ultimately controlled by the mother. In contrast, in $B$. undatum a larger number of smaller offspring are produced under lower temperature conditions, suggesting that in colder years a higher number of less energetically fit offspring will hatch. This resource allocation, although atypical, generally results in offspring receiving a higher level of reserves under warmer conditions, which could compensate for the greater bioenergetic demand necessary for development at higher temperatures, as has previously been reported in this species (Smith et al. 2013) and other marine invertebrates (Evjemo et al. 2001, García-Guerrero et al. 2003). This result is further supported by the greater number of offspring observed developing in the $B$. undatum egg masses from Iceland, where temperatures are naturally lower than in the UK. Similar patterns have also been observed in other gastropods (e.g., Fernández et al. 2006, Collin 2012). Rapid nurse egg consumption and asynchrony in early development may be adaptations, which have evolved within B. undatum to allow for optimal survival under different thermal scenarios. Although more empty embryos were observed under warmer conditions, considering the increased bioenergetic demand at high temperature, this may promote an overall increase in survivors. Temperature clearly plays an important role in intracapsular resource partitioning in B. undatum. It could be argued that asynchronous development is a maternal strategy to allow for differing numbers of successful offspring under varying developmental temperatures; this may explain patterns of inequality in other species (e.g., Fernández et al. 2006). This would not however, explain the increase in proportion of empty embryos observed with increasing maternal investment, which appears to be of no maternal benefit.

Interestingly, increased developmental rates known to occur at higher temperatures eventually appear to limit nurse egg consumption. Head development, which begins at the veliger stage, prevents further nurse egg consumption (Smith and Thatje 2013). The data suggest that at $18^{\circ} \mathrm{C}$, the rate at which individuals develop is greater than the rate at which nurse eggs can be consumed. As a result, only a small proportion of eggs are consumed before embryos are no longer able to feed, meaning a limited amount of energy is available to them for development to the juvenile stage. The existence of empty embryos at this temperature, despite the unconsumed nurse eggs, highlights just how rapid development is.

The common occurrence of empty embryos reported here provides a unique example of the risks involved with encapsulation. In the rare examples of species exhibiting intracapsular poecilogony, a similar occurrence is observed, with seemingly empty embryos developing alongside adelphophagic embryos (e.g., Kamel et al. 2010b, Gibson and Carver 2013). In these examples however, the empty embryos are planktotrophic, and feed post hatching. In contrast, in B. undatum the empty embryos observed are direct developers and do not survive to hatching. During encapsulation, lack of survival by embryos has been noted in several species, including some vermetid gastropods (e.g., Strathmann 
and Strathmann 2006). In these examples however, the deceased embryos are understood to be consumed by surviving embryos. In this study in contrast, embryos were not consumed by siblings; between the veliger and hatching juvenile stages, embryos appear unable to feed and even the occasional dead, nurse egg-containing embryo observed within a capsule was not ingested (K. E. Smith and S. Thatje, unpublished data). Instead, empty embryos appear to be an unfortunate consequence of development and are effectively wasted. They therefore represent an unusual loss of maternal investment, uncommon in encapsulated developments studied to date. Although rare, other examples of unexploited reproductive resources exist in marine invertebrates. For example, the gastropod Lirabuccinum dirum occasionally lays capsules, which contain nurse eggs but no embryos (Rivest 1983). Additionally, capsules of B. proboscidea are sometimes opened before all nurse eggs have been ingested (Kamel et al. 2010b). In the latter example however, mothers have been proposed to consume uneaten nurse eggs following the opening of capsules. Considering the low temperature origin of neogastropods (Jablonski and Bottjer 1991), and the reduction in number of empty embryos with decreasing temperature seen here, we propose empty embryos to be an evolutionary consequence of adaptation to warmer temperatures.

A curious feature to mention is the "accidental" cannibalism observed in B. undatum. Early veligers appear to be relatively nonselective in what they consume, and occasionally, one was observed to have ingested another embryo, which had not yet begun development. Cannibalism is not uncommon during intracapsular development, and has been previously described in many species of gastropods and other marine invertebrates (e.g., Strathmann and Strathmann 2006, Kamel et al. 2010b). Generally, when cannibalism occurs, one individual will consume another in order to increase energy reserves for development. In B. undatum, however, the observed cannibalism does not have this result (K. E. Smith and S. Thatje, unpublished data). Once ingested, embryos continued development inside the mid-gut of the consumer. They then took up nurse eggs from inside the mid-gut, and eventually burst out through the thin mantle surrounding the consumer (Fig. 1d). In this "Trojan horse" scenario the victim became the "winner" and the cannibal did not survive. This appears to be a defense mechanism against sibling cannibalism, and also presents a scenario where later development can be beneficial to offspring. Here, the cannibalized embryo gains a surplus of nurse eggs without having to compete for them. A disadvantage of this is the possibility that that particular egg is digested before commencing development.

This paper contributes a unique example of the diverse outcomes of encapsulated development, contributing to discussions of the trade-off between offspring size and number, in life history theory. It illustrates the adverse effects that both sibling rivalry and environmental factors can play in defining embryonic development, highlighting the importance of understanding the roles that different variables play during development as well as how they affect maternal investment. The combined effects of temperature and competition on intracapsular resource partitioning, and ultimately offspring quality, are of particular importance given the growing attention that has been given to climate warming over recent decades. If current sea temperatures continue to rise at similar rates as those observed today (the English Channel and the southern North Sea, $0.8^{\circ} \mathrm{C}$ increase per decade; Hughes et al. 2010), temperature increases of $4-8^{\circ}$, as employed in this study, could become relevant in the next 50-100 years. Such increases in seawater temperature have the potential to cause population level changes in distribution and abundance. Initially however, the developmental plasticity observed in this species may facilitate survival, providing a balance is struck between embryos being large enough to have sufficient reserves for development and plentiful enough to sustain a population.

\section{ACKNOWLEDGMENTS}

Thanks are given to Viviers, UK for their help with adult sample collection. Thanks also go to Adam Reed, Alastair Brown, and Andrew Oliphant for help with animal maintenance, and to Andrew Oliphant for helpful discussions on the topic. This work was supported by grants from the Total Foundation (Abyss2100) to S. Thatje and the Malacological Society to K. Smith. We thank two anonymous reviewers for constructive criticism on the draft manuscript.

\section{Literature Cited}

Anger, K. 2001. The biology of decapod crustacean larvae. Crustacean Issues Volume14. A.A. Balkema, Lisse, The Netherlands.

Anger, K., G. A. Lovrich, S. Thatje, and J. A. Calcagno. 2004. Larval and early juvenile development of Lithodes santolla (Molina, 1782) (Decapoda: Anomura: Lithodidae) reared at different temperatures in the laboratory. Journal of Experimental Marine Biology and Ecology 306:217-230.

Bernardo, J. 1996. The particular maternal effect of propagule size, especially egg size: patterns, models, quality of evidence and interpretations. American Zoologist 36:216-236.

Chaparro, O., and K. Paschke. 1990. Nurse egg feeding and energy balance in embryos of Crepidula dilatata (Gastropoda: Calyptraeida) during intracapsular development. Marine Ecology Progress Series 65:183-191.

Clarke, A. 1992. Reproduction in the cold: Thorson revisited. Invertebrate Reproduction and Development 22:175-183.

Collin, R. 2012. Temperature-mediated trade-offs and changes in life-history integration in two slipper limpets (Gastropoda: Calyptraeidae) with planktotrophic development. Biological Journal of the Linnean Society 106:763-775.

Crean, A. J., and D. J. Marshall. 2009. Coping with environmental uncertainty: dynamic bet hedging as a maternal effect. Philosophical Transactions of the Royal Society B 364:1087-1096.

Cumplido, M., P. Pappalardo, M. Fernández, A. Averbuj, and G. Bigatti. 2011. Embryonic development, feeding and intracapsular oxygen availability in Trophon geversianus (Gastropoda: Muricidae). Journal of Molluscan Studies 77: 429-436. 
Dziminski, M. A., and R. A. Alford. 2005. Patterns and fitness consequences of intraclutch variation in egg provisioning in tropical Australian frogs. Oecologia 146:98-109.

Evjemo, J. O., T. L. Danielsen, and Y. Olsen. 2001. Losses of lipid, protein and $n-3$ fatty acids in enriched Artemia franciscana starved at different temperatures. Aquaculture 193:65-80.

Fernández, M., P. Pappalardo, and K. Jeno. 2006. The effects of temperature and oxygen availability on intracapsular development of Acanthina monodon (Gastropoda: Muricidae). Revista Chilena de Historia Natural 79:155-167.

Fox, C. W., and M. E. Czesak. 2000. Evolutionary ecology of progeny size in arthropods. Annual Review of Entomology 45:341-369.

Gallardo, C. 1979. Developmental pattern and adaptations for reproduction in Nucella crassilabrum and other muricacean gastropods. Biological Bulletin 157:453-463.

García-Guerrero, M., H. Villarreal, and I. S. Racotta. 2003. Effect of temperature on lipids, proteins, and carbohydrates levels during development from egg extrusion to juvenile stage of Cherax quadricarinatus (Decapoda: Parastacidae). Comparative Biochemistry and Physiology Part A 135:147154.

Gibson, G., and D. Carver. 2013. Effects of extra-embryonic provisioning on larval morphology and histogenesis in Boccardia proboscidea (Annelida, Spionidae). Journal of Morphology 274:11-23.

Gibson, G., I. G. Paterson, H. Taylor, and B. Woolridge. 1999. Molecular and morphological evidence of a single species, Boccardia proboscidea (Polychaeta: Spionidae), with multiple development modes. Marine Biology 134:743-751.

González, K. A., and C. S. Gallardo. 1999. Embryonic and larval development of the muricid snail Chorus giganteus (Lesson, 1829) with an assessment of the developmental nutrition source. Ophelia 51:77-92.

Hadfield, M. G. 1989. Latitudinal effects on juvenile size and fecundity in Petaloconchus (Gastropoda). Bulletin of Marine Science 45:369-376.

Hughes, S. L., N. P. Holliday, J. Kennedey, D. I. Berry, E. C. Kent, T. Sherwin, S. Dye, M. Inall, T. H. Shammon, and T. Smythe. 2010. Temperature (air and sea). MCCIP Annual Report Card 2010-11, MCCIP Science Review. www.mccip. org.uk/arc

Jablonski, D., and D. J. Bottjer. 1991. Environmental patterns in the origins of higher taxa: the post-Paleozoic fossil record. Science 252:1831-1833.

Kamel, S. J., R. K. Grosberg, and D. J. Marshall. $2010 a$. Family conflicts in the sea. Trends in Ecology and Evolution 25:442-449.

Kamel, S. J., F. X. Oyarzun, and R. K. Grosberg. $2010 b$. Reproductive biology, family conflict, and size of offspring in marine invertebrates. Integrative and Comparative Biology 50:619-629.

Kesäniemi, J. E., P. D. Rawson, S. M. Lindsay, and K. E. Knott. 2012. Phylogenetic analysis of cryptic speciation in the polychaete Pygospio elegans. Ecology and Evolution 2:9941007.

Kingsolver, J. G., and R. B. Huey. 2008. Size, temperature, and fitness: three rules. Evolutionary Ecology Research 10:251268.

Koops, M. A., J. A. Hutchings, and B. K. Adams. 2003. Environmental predictability and the cost of imperfect information: influences on offspring size variability. Evolutionary Ecology Research 5:29-42.

Krug, P. J., D. Gordon, and M. R. Romero. 2012. Seasonal polyphenism in larval type: rearing environment influences the development mode expressed by adults in the sea slug Alderia willowi. Integrative and Comparative Biology 52:161172 .
Kudo, S. 2001. Intraclutch egg-size variation in acanthosomatid bugs: adaptive allocation of maternal investment? Oikos 92: 208-214.

Lardies, M. A., and M. Fernández. 2002. Effect of oxygen availability in determining clutch size in Acanthina monodon. Marine Ecology Progress Series 239:139-146.

Lawler, A., and B. Vause. 2009. Whelk biology. Final report. http://www.cefas.defra.gov.uk/media/358431/whelkfspfinalreport. pdf

Marshall, D. J., R. M. Allen, and A. J. Crean. 2008a. The ecological and evolutionary importance of maternal effects in the sea. Oceanography and Marine Biology: An Annual Review 46:203-250.

Marshall, D. J., R. Bonduriansky, and L. F. Bussière. 2008b. Offspring size variation within broods as a bet-hedging strategy in unpredictable environments. Ecology 89:25062517.

Marshall, D. J., C. N. Cook, and R. B. Emlet. 2006. Offspring size effects mediate competitive interactions in a colonial marine invertebrate. Ecology 87:214-225.

Marshall, D. J., and M. J. Keough. 2007. The evolutionary ecology of offspring size in marine invertebrates. Advances in Marine Biology 53:1-60.

Martel, A., D. H. Larrivee, and J. H. Himmelman. 1986. Behaviour and timing of copulation and egg-laying in the neogastropod Buccinum undatum. Journal of Experimental Marine Biology and Ecology 96:27-42.

McGinley, M. A., D. H. Temme, and M. A. Geber. 1987. Parental investment in offspring in variable environments: theoretical and empirical considerations. American Naturalist $130: 370-398$

Moran, A., and R. Emlet. 2001. Offspring size and performance in variable environments: field studies on a marine snail. Ecology 82:1597-1612.

Mousseau, T. A., and C. W. Fox. 1998. The adaptive significance of maternal effects. Trends in Ecology and Evolution 13:403-407.

Ojeda, J. A., and O. R. Chaparro. 2004. Morphological, gravimetric, and biochemical changes in Crepidula fecunda (Gastropoda: Calyptraeidae) egg capsule walls during embryonic development. Marine Biology 144:263-269.

Oyarzun, F. X., and R. R. Strathmann. 2011. Plasticity of hatching and the duration of planktonic development in marine invertebrates. Integrative and Comparative Biology 51:81-90.

Parker, G. A., N. J. Royle, and I. R. Hartley. 2002 Intrafamilial conflict and parent investment: a synthesis. Philosophical Transactions of the Royal Society of London Series B 357:295-307.

Philippi, T., and J. Seger. 1989. Hedging one's evolutionary bets, revisited. Trends in Ecology and Evolution 4:41-44.

Portmann, A. 1925. Der Einfluss der Nähreier auf die Larvenentwicklung von Buccinum und Purpura. Zoomorphology 3:526-541.

Rhymer, J. M. 1988. The effect of egg size variability on thermoregulation of Mallard (Anas platyrhynchos) offspring and its implications for survival. Oecologia 75:20-24.

Rivest, B. R. 1983. Development and the influence of nurse egg allotment on hatching size in Searlesia dira (Reeve, 1846) (Prosobranchia: Buccinidae). Journal of Experimental Marine Biology and Ecology 69:217-241.

Slatkin, M. 1974. Hedging one's evolutionary bets. Nature 250: 704-705.

Smith, C. C., and S. D. Fretwell. 1974. The optimal balance between size and number of offspring. American Naturalist 108:499-506.

Smith, K. E., and S. Thatje. 2013. Nurse egg consumption and intracapsular development in the common whelk Buccinum undatum (Linnaeus 1758). Helgoland Marine Research 67: 109-120. 
Smith, K. E., S. Thatje, and C. Hauton. 2013. Effects of temperature on early ontogeny in the common whelk Buccinum undatum (L. 1785); bioenergetics, nurse egg partitioning and developmental success. Journal of Sea Research 79:32-39.

Spight, T. M. 1976. Ecology of hatching size for marine snails. Oecologia 24:283-294.

Strathmann, M. F., and R. R. Strathmann. 2006. A vermetid gastropod with complex intracapsular cannibalism of nurse eggs and sibling larvae and a high potential for invasion. Pacific Science 60:97-108.
Strathmann, R. R. 1995. Peculiar constraints on life histories imposed by protective or nutritive devices for embryos. American Zoologist 35:426-433.

Thorson, G. 1950. Reproductive and larval ecology of marine bottom invertebrates. Biological Reviews 25:1-45.

Valentinsson, D. 2002. Reproductive cycle and maternal effects on offspring size and number in the neogastropod Buccinum undatum (L.). Marine Biology 140:1139-1147.

Vance, R. R. 1973. On reproductive strategies in marine benthic invertebrates. American Naturalist 107:339-352. 
Queries for ecol-94-10-21

This manuscript/text has been typeset from the submitted material. Please check this proof carefully to make sure there have been no font conversion errors or inadvertent formatting errors. Allen Press. 